\section{Morphogenetic Response of Lilium michiganense to Four Auxin-type Plant Growth Regulators In Vitro}

\author{
James Robert Ault ${ }^{2}$ and Sandy S. Siqueira ${ }^{1}$ \\ Chicago Botanic Garden, Ornamental Plant Research, 1000 Lake Cook \\ Road, Glencoe, IL 60022 \\ Additional index words. tissue culture, propagation, callus induction, Michigan lily
}

\begin{abstract}
Shoot, root, and callus induction were examined in the North American lily Lilium michiganense in response to treatment with four auxin-type plant growth regulators (PGR). Seed from controlled crosses were aseptically excised from slightly immature capsules and cultured in vitro on Murashige and Skoog basal medium and vitamins with $30 \mathrm{~g} \cdot \mathrm{L}^{-1}$ sucrose, $7.0 \mathrm{~g} \cdot \mathrm{L}^{-1}$ agar, and a $\mathrm{pH}=5.7$. Seed were maintained at $20^{\circ} \mathrm{C}$ with a 14-h photoperiod. After 5.0 to 5.5 months, leaves and roots were removed from seedlings, the bulbs transversely sectioned, then the bulb sections cultured cut-surface down on the identical medium supplemented with $0.0,1.0,2.0,4.0$, or $8.0 \mu \mathrm{M}$ dicamba, picloram, K-NAA, or 2,4-D. Morphogenetic response was tabulated 4 months after treatment. Shoot formation was promoted by treatment with dicamba, picloram, and K-NAA in comparison with the control ( 2.5 shoots/explant). Shoot formation varied significantly in response to individual dicamba, picloram, and 2,4-D concentrations. A maximum of 7.9 shoots per explant was promoted by $4.0 \mu \mathrm{M}$-NAA and $1.0 \mu \mathrm{M}$ dicamba, respectively. Root and callus formation also varied significantly between PGR treatments. Root formation was inhibited by dicamba, picloram, and 2,4-D treatments in comparison with the control $(100 \%$ rooting); callus formation was promoted by dicamba, picloram, and K-NAA treatments in comparison with the control $(15 \%$ callusing).
\end{abstract}

The Michigan lily, Lilium michiganense Farw., is indigenous to North America. Although distributed over a broad geographical area east of the Mississippi River, the species is in decline as a result of habitat destruction, human removal, and deer predation. It is listed as threatened in Tennessee and endangered in New York. Lilium michiganense is most closely related to Lilium canadense L., which also occurs broadly over eastern North America yet is also in decline as a result of the same pressures. Lilium canadense is listed as rare in Indiana, vulnerable in New York, and threatened in Rhode Island and Tennessee. The close relationship of these two taxa is supported by natural interspecific hybrids reported from Ohio and New York (Adams and Dress, 1982).

Lilium michiganense is quite attractive with its whorled foliage and orange turkscap flowers gracefully arranged in a loose inflorescence atop stems to $2.0 \mathrm{~m}$. However, it is rarely cultivated as a result of its more exacting cultural requirements, propagation difficulties, and slow growth to maturity from seed in comparison with more commonly cultivated lilies. Although it has been

Received for publication 22 Feb. 2008. Accepted for publication 10 June 2008

${ }^{1}$ Current address: Department of Botany \& Zoology, University of Stellenbosch, Private Bag X1, Matieland 7602, South Africa.

${ }^{2}$ To whom reprint requests should be addressed; e-mail jault@chicagobotanic.org artificially hybridized with $L$. canadense, $L$. michauxii (McRae, 1998), and perhaps a few other taxa, no selected forms or hybrids from this species seem to currently be in cultivation. The senior author (JRA) is using this species along with other North American lily taxa to develop selections or hybrids more amenable to garden cultivation. Some of the research tools being used in this germplasm improvement program include embryo/ovule rescue from wide interspecific crosses, polyploid induction, and in vitro propagation. These studies depend on effective tissue culture protocols. There appears to be only one previously published report on the tissue culture of this taxon (Mori et al., 2005). Therefore, shoot, root, and callus induction were examined in $L$. michiganense in response to treatment with four auxin-type plant growth regulators (PGRs) in anticipation of developing further tissue culture protocols with this and its closely related taxa.

\section{Materials and Methods}

Lilium michiganense plants from a single plant population of local provenance but being grown under cultivation were crosspollinated under controlled conditions to exclude natural pollinators. Slightly immature, nondehisced fruit were removed $69 \mathrm{~d}$ after pollination. Fruit were surface-disinfested for $1 \mathrm{~min}$ in $70 \%$ ethanol followed by $15 \mathrm{~min}$ in a $50 \%$ sodium hypochlorite solution containing three drops of surfactant
Tween 80 per $500 \mathrm{~mL}$ of solution and then rinsed in sterile water for $10 \mathrm{~min}$. Seed were aseptically excised and cultured in vitro on Murashige and Skoog (Murashige and Skoog, 1962) basal medium and vitamins with $30 \mathrm{~g} \cdot \mathrm{L}^{-1}$ sucrose, $7.0 \mathrm{~g} \cdot \mathrm{L}^{-1}$ agar, and a $\mathrm{pH}=5.7$. Seed and all subsequent cultures were maintained at $20{ }^{\circ} \mathrm{C}$ in the light with a 14-h photoperiod and $30 \mu \mathrm{mol} \cdot \mathrm{m}^{-2} \cdot \mathrm{s}^{-1}$ [measured with a LI-190SA Quantum Sensor (LICOR, Lincoln, NE)] provided by two $40-\mathrm{W}$ cool white fluorescent lamps. After 5 months, leaves and roots were removed from seedlings, the remaining bulbs (each $\approx 4 \mathrm{~mm}$ tall) transversely sectioned, then the bulb sections cultured cut-surface down on the identical medium supplemented with $0.0,1.0,2.0,4.0$, or $8.0 \mu \mathrm{M}$ dicamba, picloram, K-NAA, or 2,4-D. The PGRs and concentrations were selected based on previous reports of their use for other Lilium taxa (Famelaer et al., 1996; Haensch, 1996; Okazaki and Koizumi, 1995; Pelkonen and Kauppi, 1999; Tribulato et al., 1997). PGRs were added to medium before autoclaving, except dicamba, which was dissolved in 50\% ethanol and added after medium autoclaving. Media for all cultures were autoclaved at $121{ }^{\circ} \mathrm{C}$ for $15 \mathrm{~min}$, then poured into presterilized, disposable $100 \mathrm{~mm}$ $\times 15$-mm petri dishes, $\approx 25 \mathrm{~mL}$ of medium per dish. Approximately 25 seed were sown in each petri dish for the seed germination stage. Two sectioned bulbs for a total of four explants were placed in each petri dish for the growth regulator study.

Experimental design and statistical analysis. For each experiment, 16 explants (one-half of a transversely sectioned bulb each) were randomly assigned to each PGR treatment. The experiment was conducted three times for a total of 48 explants per treatment. Morphogenetic response (number of shoots produced per explant, percent of explants forming roots, and percent of explants forming callus) was tabulated 4 months after placement of explants on media. Data were subjected to analysis of variance and polynomial regression (linear and quadratic level). Rooting percentages were transformed using arcsine before statistical analysis (nontransformed data presented in Table 3). All pairwise comparisons of mean values were analyzed using the TukeyKramer test. Data were analyzed using CoStat statistical software (CoHort Software, Berkeley, CA).

\section{Results and Discussion}

Shoot production was promoted overall by treatment with dicamba, picloram, and K-NAA (Table 1) in comparison with the control (2.5 shoots/explant). Shoot production varied significantly among the PGRs and also among the different concentrations within the PGRs dicamba, picloram, and 2,4-D. A maximum of 7.9 shoots per explant was promoted by $4.0 \mu \mathrm{M}$ K-NAA and $1.0 \mu \mathrm{M}$ dicamba, respectively. Callus and root production also varied significantly among PGR treatments. Callus production (Table 2) was 
Table 1. Shoot proliferation from Lilium michiganense explants in response to 4-month treatment in vitro with the PGRs dicamba, picloram, K-NAA, or 2,4-D.

\begin{tabular}{|c|c|c|c|c|c|}
\hline \multirow[b]{2}{*}{ PGR $(\mu \mathrm{M})$} & \multicolumn{5}{|c|}{ Number of shoots per explant } \\
\hline & $\overline{\text { Control }}$ & Dicamba & Picloram & K-NAA & $2,4-\mathrm{D}$ \\
\hline$\overline{0.0}$ & $2.5 \mathrm{def}^{2}$ & & & & \\
\hline 1.0 & & $7.9 \mathrm{a}$ & $5.6 \mathrm{bc}$ & $7.0 \mathrm{ab}$ & $2.7 \mathrm{def}$ \\
\hline 2.0 & & $5.8 \mathrm{bc}$ & $4.3 \mathrm{~cd}$ & $7.3 \mathrm{ab}$ & $2.3 \mathrm{ef}$ \\
\hline 4.0 & & $3.2 \mathrm{de}$ & $3.0 \mathrm{def}$ & $7.9 \mathrm{a}$ & $1.4 \mathrm{ef}$ \\
\hline 8.0 & & $1.2 \mathrm{f}$ & $1.6 \mathrm{ef}$ & $6.9 \mathrm{ab}$ & $1.3 \mathrm{ef}$ \\
\hline Overall source of variation & $\mathrm{df}$ & F value & & & \\
\hline All treatments & 16 & $42.1 * *$ & & & \\
\hline Contrast control versus NAA & 1 & $123.6^{* *}$ & & & \\
\hline Contrast control versus picloram & 1 & $6.7^{*}$ & & & \\
\hline Contrast control versus dicamba & 1 & $23.7 * *$ & & & \\
\hline Contrast control versus $2,4-\mathrm{D}$ & 1 & $1.7 \mathrm{NS}$ & & & \\
\hline Contrast PGRs & 3 & $136.7 * *$ & & & \\
\hline Error & 792 & & & & \\
\hline \multicolumn{6}{|l|}{ Regression analysis within PGRs } \\
\hline Linear & ** & $* *$ & NS & ** & \\
\hline Quadratic & NS & NS & NS & NS & \\
\hline
\end{tabular}

${ }^{\mathrm{z}}$ Means followed by a common letter are not significantly different at $P \leq 0.05$ according to the TukeyKramer range test.

Ns, *, ** Nonsignificant or significant at $P \leq 0.05$ or 0.01 , respectively.

PGRs, Plant growth regulators.

Table 2. Callus production from Lilium michiganense explants in response to 4-month treatment in vitro with the PGRs dicamba, picloram, K-NAA, or 2,4-D.

\begin{tabular}{|c|c|c|c|c|c|}
\hline \multirow[b]{2}{*}{ PGR $(\mu \mathrm{M})$} & \multicolumn{5}{|c|}{ Percent of explants producing callus ${ }^{2}$} \\
\hline & $\overline{\text { Control }}$ & Dicamba & Picloram & K-NAA & $2,4-\mathrm{D}$ \\
\hline$\overline{0.0}$ & $19 \mathrm{~cd}^{\mathrm{y}}$ & & & & \\
\hline 1.0 & & $96 \mathrm{a}$ & $94 \mathrm{a}$ & $88 \mathrm{ab}$ & $77 \mathrm{abc}$ \\
\hline 2.0 & & $94 \mathrm{a}$ & $85 \mathrm{ab}$ & $94 \mathrm{ab}$ & $38 \mathrm{abcd}$ \\
\hline 4.0 & & $92 \mathrm{ab}$ & $79 \mathrm{ab}$ & $98 \mathrm{a}$ & $25 \mathrm{bcd}$ \\
\hline 8.0 & & $91 \mathrm{ab}$ & $75 \mathrm{abc}$ & $98 \mathrm{a}$ & $6 \mathrm{~d}$ \\
\hline Overall source of variation & $\mathrm{df}$ & F value & & & \\
\hline All treatments & 16 & $6.2 * *$ & & & \\
\hline Contrast control versus NAA & 1 & $30.2^{* *}$ & & & \\
\hline Contrast control versus picloram & 1 & $24.7^{* *}$ & & & \\
\hline Contrast control versus dicamba & 1 & $28.8^{* *}$ & & & \\
\hline Contrast control versus 2,4-D & 1 & $1.6 \mathrm{NS}$ & & & \\
\hline Contrast PGRs & 3 & $20.2 * *$ & & & \\
\hline Error & 34 & & & & \\
\hline \multicolumn{6}{|l|}{ Regression analysis within PGRs } \\
\hline Linear & NS & NS & NS & ** & \\
\hline Quadratic & NS & NS & NS & NS & \\
\hline
\end{tabular}

${ }^{\mathrm{z}}$ Explants producing callus clumps greater than $3 \mathrm{~mm}$ in diameter.

${ }^{\mathrm{y}}$ Means followed by a common letter are not significantly different at $P \leq 0.05$ according to the TukeyKramer range test.

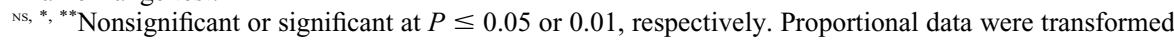
with arcsine before regression analysis. Nontransformed data presented.

PGRs, Plant growth regulators.

promoted overall by dicamba, picloram, and K-NAA treatments in comparison with the control ( $15 \%$ callusing). Although overall 2,4-D treatment did not have a significant effect on callus production, a significant difference within the 2,4-D treatments indicates individual 2,4-D concentrations may have an effect on callus production. Root production (Table 3 ) was inhibited overall by dicamba, picloram, and 2,4-D treatments in comparison with the control (100\% rooting), whereas NAA overall did not inhibit root production. There were no significant differences in root production between concentrations tested within each PGR. The most morphogenetically responsive explants exhibited axillary/adventitious shoots, callus masses, and adventitious roots in complex clumps (Fig. 1).
Visual inspection of the cultures indicated that shoot induction occurred principally as axillary or adventitious shoots arising directly on the bulb explants and not as shoots arising from callus. Lilium bulbs naturally divide to form new bulbs. Removal of individual bulb scales can induce adventitious bulblet formation without the need for any PGR treatment, a process known as scaling that is commonly used to propagate lilies (McRae, 1998). Thus, it is not surprising that the sectioned bulbs used as explants in this study also produced shoots on the control medium (no PGR treatment) an average of 2.5 shoots/explant. What is interesting is that three of the four PGRs tested (dicamba, picloram K-IBA) stimulated significantly higher shoot production rates than for the control (Table 1). Typically, in vitro propa- gation systems use either a combination of cytokinins and auxins (in proportional concentrations or ratios favoring the former) or cytokinins alone to induce shoot proliferation. Similar results have been reported in lilies as well. Maesato et al. (1994) reported $4.92 \mu \mathrm{M} 2 \mathrm{iP}+0.54 \mu \mathrm{M}$ NAA was effective in stimulating bulblet formation from bulb scale explants of Lilium japonicum. Dabrowski et al. (1992) reported maximum regeneration from bulb scales of Lilium 'Sonnentiger' occurred in response to $1.48 \mu \mathrm{M} 2 \mathrm{iP}+0.54$ $\mu \mathrm{M}$ NAA. However, auxins alone have also been reported to be effective for inducing shoot formation such as in Lilium longiflorum (Nhut et al., 2001; Stimart and Ascher, 1978) in response to NAA treatments. The former authors hypothesized this may be the result of naturally high endogenous concentrations of cytokinins in L. longiflorum tissues. NAA appears to be the auxin-type PGR of choice to use alone or in combination with cytokinins for shoot induction in lilies, a finding this study also supports. Although auxin-type PGRs alone stimulated shoot production in this study, further research is suggested to compare the effect of cytokinins plus auxins with auxins alone on shoot induction in $L$. michiganense.

Callus production can be of interest in a crop improvement program as a propagation tool through organogenic and somatic embryogenic induction. Inductive callus lines are also useful for genetic manipulation practices such as transformation, protoplast isolation and fusion, and polyploid induction. Callus induction and subsequent plant regeneration has been reported for a wide array of lilies in response to various auxin-type PGRs and concentrations (Kim et al., 2003; Mori et al., 2005; Okazaki and Koizumi, 1995; Pelkonen and Kauppi, 1999; Tribulato et al., 1997). Only one other study has examined callus induction in L. michiganense or in its closely related taxon, L. canadense. No callus was induced from either of these taxa in response to the one PGR tested, $4.1 \mu \mathrm{M}$ picloram (Mori et al., 2005). In contrast, our study resulted in $79 \%$ callus induction of $L$. michiganense in response to $4.0 \mu \mathrm{M}$ picloram (Table 2). These differences are likely explained by explant differences between the two studies. We used actively growing bulb explants, whereas the study by Mori et al. (2005) used nongerminated seed. Lilium michiganense seed exhibits a delayed hypogeal germination response, requiring alternating 2-month periods of warm and cool moist treatment for germination. The $L$. michiganense seed used by Mori et al. (2005) was probably dormant given their culture conditions and thus likely nonresponsive to PGR callus induction treatment. Our study is, therefore, the first to indicate that L. michiganense seedling explants can produce callus in response to a variety of auxintype PGRs and concentrations. Presumptive embryo-like bodies were observed on callus produced by several of the PGRs used in this study; however, none of these developed further on transfer to PGR-free medium for 
Table 3. Root production from Lilium michiganense explants in response to 4-month treatment in vitro with the PGRs dicamba, picloram, K-NAA, or 2,4-D.

\begin{tabular}{lccccc}
\hline & \multicolumn{4}{c}{ Percent of explants producing roots } \\
\cline { 2 - 6 } PGR $(\mu \mathrm{M})$ & Control & Dicamba & Picloram & K-NAA & $2,4-\mathrm{D}$ \\
\hline 0.0 & $100 \mathrm{a}^{\mathrm{z}}$ & & & & \\
1.0 & $33 \mathrm{de}$ & $42 \mathrm{cde}$ & $98 \mathrm{ab}$ & $88 \mathrm{abcd}$ & \\
2.0 & $23 \mathrm{e}$ & $48 \mathrm{bcde}$ & $96 \mathrm{abc}$ & $96 \mathrm{abc}$ & \\
4.0 & $51 \mathrm{bcde}$ & $68 \mathrm{abcde}$ & $98 \mathrm{ab}$ & $81 \mathrm{abcd}$ & \\
8.0 & $52 \mathrm{bcde}$ & $51 \mathrm{bcde}$ & $100 \mathrm{a}$ & $86 \mathrm{abcd}$ & \\
Overall source of variation & $\mathrm{df}$ & F value & & \\
$\quad$ All treatments & 16 & $7.3^{* *}$ & & \\
Contrast control versus NAA & 1 & $0.3 \mathrm{NS}$ & & \\
Contrast control versus picloram & 1 & $24.0^{* *}$ & & \\
Contrast control versus dicamba & 1 & $34.9^{* *}$ & & \\
Contrast control versus 2,4-D & 3 & 1 & $4.2^{*}$ & \\
$\quad$ Contrast PGRs & $30.9^{* *}$ & & \\
Error & 34 & & & \\
Regression analysis within PGRs & & & $\mathrm{NS}$ & $\mathrm{NS}$ \\
$\quad$ Linear & $\mathrm{NS}$ & $\mathrm{NS}$ & $\mathrm{NS}$ & $\mathrm{NS}$ \\
Quadratic & $\mathrm{NS}$ & $\mathrm{NS}$ & $\mathrm{NS}$ & \\
\hline
\end{tabular}

${ }^{\mathrm{z}}$ Means followed by a common letter are not significantly different at $P \leq 0.05$ according to the TukeyKramer range test.

${ }_{\text {Ns, }, * * *}$ Nonsignificant or significant at $P \leq 0.05$ or 0.01 , respectively. Proportional data were transformed with arcsine before regression analysis. Nontransformed data presented.

PGRs, Plant growth regulators.

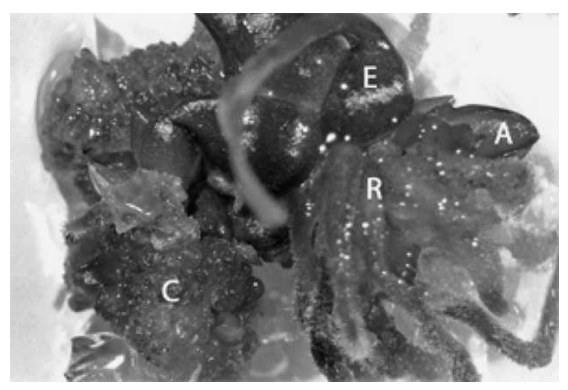

Fig. 1. Root (R), adventitious shoot (A), and callus (C) formation in vitro from a transversely sectioned Lilium michiganense seedling bulb explant (E) after 4 months culture on Murashige and Skoog medium supplemented with $2 \mu \mathrm{M}$ K-NAA.

an additional 3 months of culture (data not reported). It is possible that either the callus was noninductive or culture conditions were not optimized for shoot or embryo induction. For example, Okazaki and Koizumi (1995) reported shoot induction from callus was stimulated for Lilium $\times$ formolongi by either 6 months culture on PGR-free medium or a reduction of sucrose concentration from $3 \%$ to $1 \%$. Conversely, Mori et al. (2005) reported shoot induction from callus for a broad range of lilies was stimulated by only 2 months culture on PGR-free medium. Further research is, therefore, suggested to elucidate a protocol for in vitro callus induction and subsequent shoot formation for L. michiganense.

Although our study indicated L. michiganense explants are capable of producing roots in the presence of various auxin-type PGRs and at various concentrations (Table 3 ), only treatment with K-NAA resulted in as great a percentage root induction as on PGR-free medium (100\% induction). Many of the roots formed in vitro appeared to arise from either the original explants or from the generated bulbs. Callus production for many of the cultures precluded a definitive determination of the exact source of the generated roots (e.g., from initial explants, regenerated bulbs, or callus). In vitro rooting of nonrooted, intact regenerated shoots free of callus was not examined as part of this study. However, 40 of the original seedlings used as explant sources were maintained in culture for the duration of this study. All 40 shoots produced roots on PGR-free medium and were successfully outplanted to the greenhouse (data not reported), indicating a good likelihood of being able to root this taxon in vitro. For this taxon, treatment either with NAA or culture on a PGR-free medium would be recommended for in vitro rooting. These results support the literature that indicates a broad diversity of Lilium taxa root readily in vitro on PGRfree media (Kim et al., 2003; Mori et al., 2005; Pelkonen and Kauppi, 1999; Tribulato et al., 1997) or on media supplemented with $0.54 \mu \mathrm{M}$ NAA (Chang et al., 2000; Dabrowski et al., 1992). Only one study, with the species Lilium nepalense, reported a marked improvement of rooting in vitro with either IAA or IBA treatment compared with PGRfree (on half-strength Murashige and Skoog medium); both $1 \mu \mathrm{M}$ IAA and $1 \mu \mathrm{M}$ IBA resulted in $100 \%$ rooting, whereas the PGRfree medium resulted in $31 \%$ rooting.

In conclusion, a variety of auxin-type PGRs and concentrations may be used to stimulate shoot, root, and callus production in the North American native lily, Lilium michiganense. Specific type and concentration of PGR selected will depend on the desired morphogenetic response. Shoot proliferation genotypes for cultivation or to preserve rare in vitro can be used to propagate superior genotypes. Rooting in vitro can facilitate the transfer of in vitro-derived shoots to greenhouse- or field-growing conditions. Finally, callus induction can be used for propagation or genetic manipulation studies such as in vitro polyploid induction. The results of this study are being used by the senior author for the propagation and polyploid induction of this and related taxa.

\section{Literature Cited}

Adams, R.M. and W.J. Dress. 1982. Nodding Lilium species of eastern North America Liliaceae. Baileya 21:165-188.

Chang, C., C.-T. Chen, Y.-C. Tsai, and W.-C. Chang. 2000. A tissue culture protocol for propagation of a rare plant, Lilium speciosum Thunb. var. gloriosoides Baker. Bot. Bull. Acad. Sin. 41:139-142.

Dabrowski, J., M. Dabski, and D. Kozak. 1992. The influence of some growth regulators on regeneration of lily bulbs in vitro. Acta Hort. 325:537-541.

Famelaer, I., E. Ennik, J.M. van Tuyl, H. Meijer, and C. Creemers-Molenaar. 1996. The establishment of suspension and meristem cultures for the development of a protoplast regeneration and fusion system in lily. Acta Hort. 414: 161-168.

Haensch, K.-T. 1996. Plant regeneration through somatic embryogenesis in different genotypes of Lilium-hybrids. Gartenbauwissenschaft 61 : 214-218.

Kim, S.K., J.S. Lee, K.H. Huang, and B.J. Ahn. 2003. Utilization of embryogenic cell cultures for the mass production of bulblets in Oriental and Easter Lilies. Acta Hort. 625:253 259.

Maesato, K., K. Sharada, H. Fukui, T. Hara, and K.S. Sarma. 1994. In vitro bulblet regeneration from bulbscale explants of Lilium japonicum Thunb. Effect of plant growth regulators and culture environment. J. Hort. Sci. 69:289-297.

McRae, E.A. 1998. Lilies. A guide for growers and collectors. Timber Press, Portland, OR.

Mori, S., Y. Adachi, S. Horimoto, S. Suzuki, and M. Nakano. 2005. Callus formation and plant regeneration in various Lilium species and cultivars. In Vitro Cell. Dev. Biol. Plant 41: 783-788.

Murashige, T. and F. Skoog. 1962. A revised medium for rapid growth and bioassays with tobacco tissue cultures. Physiol. Plant. 15:473479.

Nhut, T.D., B.V. Le, M. Tanaka, and K. Tran Thanh Van. 2001. Shoot induction and plant regeneration from receptacle tissues of Lilium longiflorum. Sci. Hort. 87:131-138.

Okazaki, K. and M. Koizumi. 1995. Callus formation and regeneration of some species of Lilium. Acta Hort. 392:97-106.

Pelkonen, V.-P. and A. Kauppi. 1999. The effect of auxins on the regeneration of lily (Lilium regale Wil.) cells by somatic embryogenesis and organogenesis. Int. J. Plant Sci. 160:483490.

Stimart, D.P. and P.D. Ascher. 1978. Tissue culture of bulb scale sections for asexual propagation of Lilium. J. Amer. Soc. Hort. Sci. 103:182184.

Tribulato, A., P.C. Remotti, and H.J.M. Loffler. 1997. Lily regenerative callus and cell cultures for transformation. Acta Hort. 430:299-306. 